\title{
Digestibilidade Aparente de Dietas Contendo Milho ou Casca de Mandioca Como Fonte Energética e Farelo de Algodão ou Levedura como Fonte Protéica em Novilhas ${ }^{1}$ \\ Adriana de Souza Martins ${ }^{2}$, Ivanor Nunes do Prado ${ }^{3}$, Lúcia Maria Zeoula ${ }^{3}$, Antônio Ferriani Branco $^{3}$, Willian Gonçalves do Nascimento 4
}

\begin{abstract}
RESUMO - Vinte e oito novilhas, com $303 \mathrm{~kg}$ PV médio, foram usadas para determinar a digestibilidade aparente da matéria seca (MS), proteína bruta (PB), matéria orgânica (MO), energia bruta (EB), fibra em detergente ácido (FDA), fibra em detergente neutro (FDN) e amido, em dietas contendo grão de milho ou casca de mandioca e levedura ou farelo de algodão mais farinha de carne e ossos, durante sete dias. O efeito da adição de sal ou sal mineral às dietas também foi avaliado. A cinza insolúvel em ácido foi usada como indicador interno. As digestibilidades da MS, MO e EB foram maiores para as dietas contendo levedura em relação àquelas com farelo de algodão + farinha de carne e ossos. O mesmo ocorreu com a digestibilidade da PB, FDA e FDN, porém somente para as dietas contendo milho como fonte energética. Não houve influência das fontes protéicas sobre a digestibilidade do amido. A casca de mandioca apresentou maior digestibilidade dos nutrientes em comparação ao milho. O sal mineral promoveu maior digestibilidade da MS, PB, MO, FDN e amido em comparação às dietas à base de milho e sal.
\end{abstract}

Palavras-chave: casca de mandioca, digestibilidade, energia, levedura, proteína

\section{Apparent Digestibility of Diets Containing Corn or Cassava Hull as Energy Source and Cottonseed Meal or Yeast as Protein Source, in Heifers}

\begin{abstract}
Twenty-eight heifers, with average $303 \mathrm{~kg} \mathrm{LW}$ were used to determine the apparent digestibility of dry matter (DM), crude protein (CP), organic matter (OM), gross energy (GE), acid detergent fiber (ADF), neutral detergent fiber (NDF) and starch in diets containing corn or cassava hull and yeast or cottonseed meal plus meat and bone meal, during seven days. The addition effect of salt or mineralized salt to the diets was also evaluated. The acid insoluble ash was used as internal maker. The digestibility of DM, OM and GE were higher for diets containing yeast compared to those ones with cottonseed meal plus meat and bone meal. The same happens for digestibilities of CP, ADF and NDF, however, only for diets containing corn as a energy source. There was no effect of protein sources on starch digestibility. The cassava hull presented higher nutrient digestibility compared to corn grain. The mineralized salt provided higher digestibility of DM, CP, OM, NDF and starch, compared to corn based diets with salt.
\end{abstract}

Key Words: cassava hull, digestibility, energy, yeast, protein

\section{Introdução}

Na criação de ruminantes, a alimentação é responsável por grande parte dos custos ( 60 a $70 \%)$, sejam estes animais confinados ou criados extensivamente. Portanto, é de fundamental importância conhecer as características dos alimentos e seu balanceamento na formulação de rações, as quais devem ser formuladas para suprir as necessidades dos animais, explorando sua máxima capacidade digestiva, de modo a atingir seu potencial genético para o aproveitamento da ração.

Existe, hoje, uma variedade de alimentos que podem ser utilizados na alimentação de ruminantes. Entretanto, seu valor nutricional e sua qualidade são determinados por complexa interação entre os nutrientes e os microrganismos do trato digestivo, nos processos de digestão, absorção, transporte e utilização de metabólitos, além da própria condição fisiológica do animal.

A mandioca é um alimento que contém $3,04 \mathrm{Mcal} / \mathrm{kg}$ de energia metabolizável (EM), sendo, portanto, semelhante à EM do milho, com 3,25 Mcal/kg (NATIONAL RESEARCH COUNCIL - NRC, 1996). Seus diferentes resíduos (casca de mandioca, farinha de varredura, entre outros) podem ser utilizados nas rações animais. Seu potencial para produção animal é alto, desde que sua produção econômica, em larga escala, seja viabilizada.

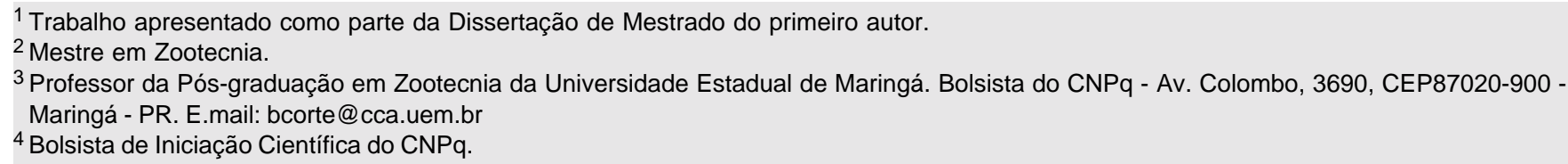


A digestão é um processo de conversão de macromoléculas do alimento para compostos simples que podem ser absorvidos a partir do trato gastrointestinal. Medidas de digestibilidade têm contribuído significativamente para o desenvolvimento de sistemas, a fim de descrever o valor nutritivo dos alimentos (VAN SOEST, 1994).

Pesquisas na área de nutrição de ruminantes têm evidenciado a importância da população microbiana tanto na digestão de carboidratos como na contribuição da proteína microbiana para suprir os requisitos da proteína animal. Cerca de 70 a $85 \%$ da matéria seca (MS) digestível da ração são digeridos pelos microrganismos ruminais, produzindo células microbianas, amônia, metano, dióxido de carbono e ácidos graxos voláteis (COELHO da SILVA e LEÃO, 1979). Dessa forma, a digestibilidade do alimento irá refletir sobre seu aproveitamento pelos microrganismos do rúmen e expressar a capacidade do animal em utilizar, em maior ou menor escala, seus nutrientes. Segundo DUTRA et al. (1997), a digestibilidade é um dos parâmetros mais importantes para a avaliação do valor nutritivo de um alimento.

VILELA et al. (1990), avaliando o efeito da suplementação energética da silagem de capim-elefante com raspa de mandioca, com ou sem a adição de uréia, observaram que as dietas contendo silagem, uréia e raspa de mandioca apresentaram os maiores coeficientes de digestibilidade da MS, matéria orgânica (MO) e energia bruta (EB). Esses autores observaram ainda que os coeficientes de digestibilidade da parede celular foram menores para as dietas à base de silagem suplementada com raspa de mandioca, pois o amido estaria reduzindo a digestibilidade da fração fibrosa da forragem.

AROEIRA et al. (1996), estudando a degradabilidade ruminal de alguns alimentos, observaram altos valores para a degradabilidade efetiva da MS da raiz de mandioca $(90,4 \%)$. O farelo de trigo apresentou maior degradabilidade da proteína $(84,7 \%)$, seguido pelo milho (76\%). Segundo esses autores, no caso da utilização destes concentrados em dietas para vacas de alta produção (> $20 \mathrm{~kg}$ de leite/dia), estes dados devem ser considerados de tal maneira que a dieta não fique deficiente em proteína nãodegradável no rúmen.

Estudos relacionados à suplementação mineral, especialmente fósforo, magnésio e cobalto, sobre digestão do amido e dos constituintes da parede celular (celulose, hemicelulose, lignina e pectina), têm mostrado que a suplementação aumenta a utiliza- ção da forragem, devido ao aumento na degradação da celulose (KOMISARCUZ-BONY e DURAND, 1991). CHRISTIANSEN e WEBB JR. (1988), trabalhando com fêmeas da raça Angus, avaliaram o efeito da adição de fontes de minerais (calcário, óxido de magnésio e outros) sobre a digestibilidade do amido e da proteína e a absorção de aminoácidos no intestino delgado e observaram que a adição das fontes de minerais não alterou a digestibilidade do amido, porém aumentou o fluxo de proteína para o duodeno e a absorção dos aminoácidos no intestino delgado.

Oobjetivo deste trabalho foi avaliar a digestibilidade aparente de matéria seca (CDMS), proteína bruta (CDPB), matéria orgânica (CDMO), energia bruta (CDEB), fibra em detergente ácido (CDFDA), fibra em detergente neutro (CDFDN) e amido (CDAM) de dietas contendo milho ou casca de mandioca como fonte de energia e levedura ou farelo de algodão + farinha de carne e ossos como fonte de proteína, bem como a adição de sal comum ou mineral às dietas.

\section{Material e Métodos}

O experimento foi conduzido no Setor de Bovinocultura de Corte da Fazenda Experimental de Iguatemi (FEI), pertencente à Universidade Estadual de Maringá (UEM).

No ensaio de digestibilidade, foram utilizadas 28 novilhas cruzadas, com, em média, 18 meses de idade e $303 \mathrm{~kg}$, alojadas individualmente em baias de $10 \mathrm{~m}^{2}$, com comedouro e bebedouro.

Os alimentos utilizados na formulação das dietas foram constituídos de duas fontes energéticas (milho ou casca de mandioca desidratada) e duas fontes protéicas (farelo de algodão + farinha de carne e ossos ou levedura).

A casca de mandioca desidratada é um subproduto proveniente da pré-limpeza da mandioca na indústria, constituído de ponta da raiz, casca e entrecasca, chegando a apresentar $85 \%$ de umidade. Para a utilização do resíduo neste experimento, foi feita a secagem do material ao sol durante três dias, atingindo teor de, aproximadamente, $88 \%$ MS.

Foi avaliada a digestibilidade aparente de quatro dietas: 1) milho e levedura (MLE); 2) milho e farelo de algodão + farinha de carne e ossos (MFA); 3) casca de mandioca desidratada e levedura (CLE); e 4) casca de mandioca desidratada e farelo de algodão + farinha de carne e ossos (CFA). As dietas que continham farelo de algodão foram também compostas por farinha de carne e ossos $(5 \%)$. 
A composição química dos alimentos e o seu percentual de inclusão nas dietas encontram-se na Tabela 1.

A adição de sal comum ou mineral sobre a ingestão e o desempenho dos animais também foi avaliada, acrescentando-se $40 \mathrm{~g}$ de sal comum ou $80 \mathrm{~g}$ de sal mineral a cada dieta. Portanto, parte dos animais consumiu dietas acrescidas de sal comum e outra parte, de sal mineral.

A composição do sal mineral, proveniente de fonte comercial, continha, para cada $1000 \mathrm{~g}$ : cálcio,
$173,7 \mathrm{~g}$; enxofre, $20 \mathrm{~g}$; magnésio, $15 \mathrm{~g}$; zinco, 2920 mg; ferro, $784 \mathrm{mg}$; manganês, $560 \mathrm{mg}$; cobre, $800 \mathrm{mg}$; cobalto, $84 \mathrm{mg}$; iodo, $50 \mathrm{mg}$; selênio, $12 \mathrm{mg}$; vit. A, $300.000 \mathrm{UI}$; vit. D, $100.000 \mathrm{UI}$; vit. E $100 \mathrm{mg}$; niacina, $1.000 \mathrm{mg}$; e sódio, $111 \mathrm{~g}$.

Todas as dietas continham silagem de milho, fosfato e a fonte de sal (comum ou mineral). As rações foram calculadas com base na ingestão de energia metabolizável fermentável e na exigência de proteína degradável, em nível de rúmen, conforme o AGRICULTURAL AND FOOD RESEARCH COUNCIL - AFRC (1995). A

Tabela 1 - Composição química e percentual dos ingredientes nas rações $(\% \mathrm{MS})^{1}$

Table 1 - Chemical composition and percentage of the ingredient of diets (\% DM)

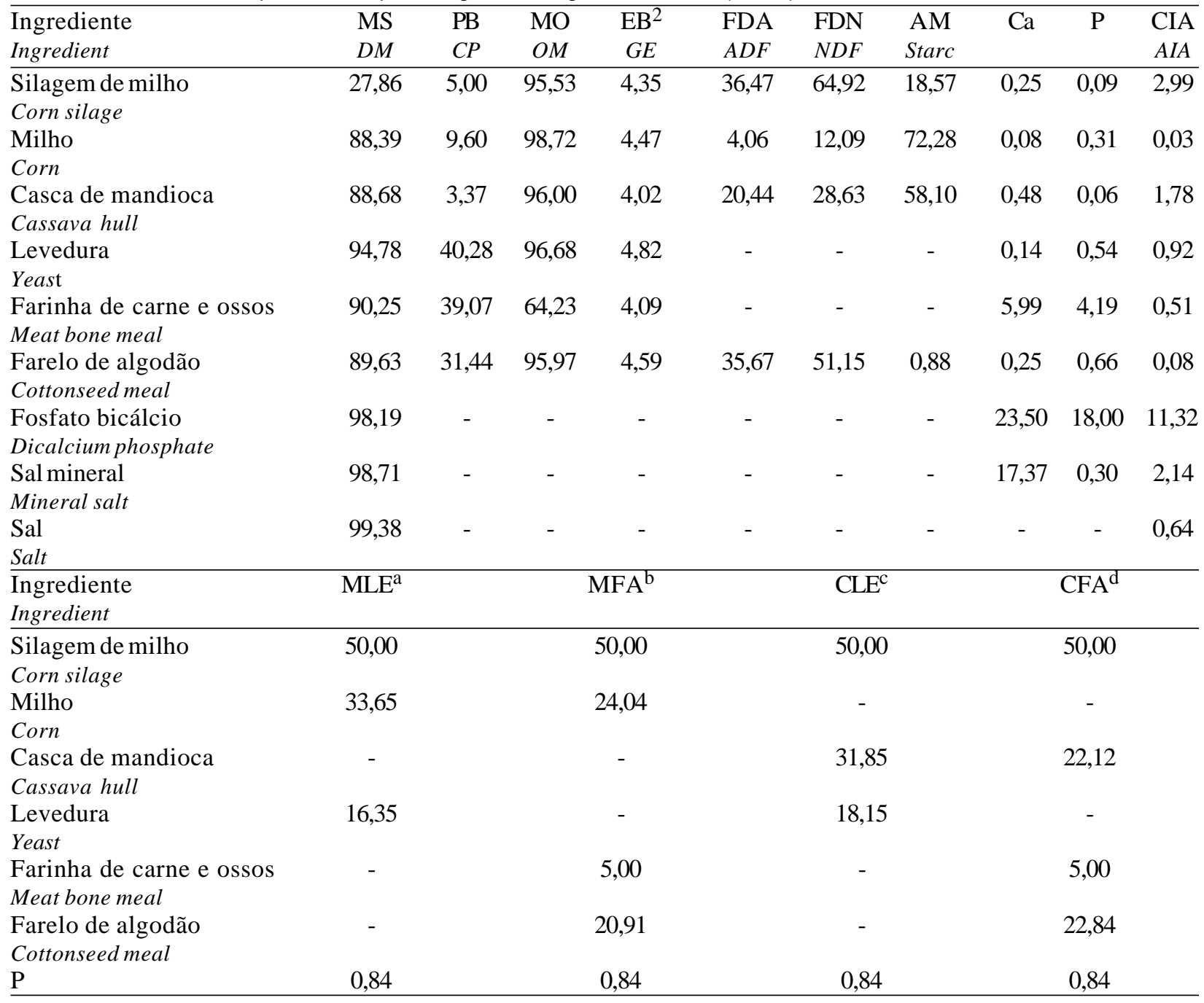

${ }_{1}^{1}$ Dados do Laboratório de Análise de Alimentos e Alimentação e Nutrição Animal - DZO/UEM.

$2 \mathrm{Mcal} / \mathrm{kg}$ de MS.

a Dieta contendo milho e levedura.

b Dieta contendo milho, farelo de algodão + farinha de carne e ossos.

c Dieta contendo casca de mandioca e levedura.

d Dieta contendo casca de mandioca, farelo de algodão + farinha de carne e ossos.

${ }^{1}$ Data obtained from the Laboratory of Feed Analysis and Animal Nutrition DZO/UEM.

a Diet containing corn and yeast.

b Diet containing corn, cottonseed meal + meat and bone meal.

${ }^{c}$ Diet containing cassava hull and yeast.

${ }^{a}$ Diet containing cassava hull, cottonseed meal + meat and bone meal. 
composição percentual (\% na MS) das quatro dietas experimentais consta da Tabela 2.

A ração completa (volumoso + concentrado) foi fornecida pela manhã $(8 \mathrm{~h})$ e à tarde $(16 \mathrm{~h})$. Os animais tiveram acesso à água limpa durante todo experimento.

$\mathrm{O}$ ensaio de digestibilidade foi realizado concomitantemente com o ensaio de desempenho. A coleta de dados teve duração de sete dias, iniciando após um período de 56 dias adaptação dos animais. Foram coletadas amostras parciais e diárias das sobras e das fezes. As amostras de sobras, fezes e alimentos que constituíram as rações foram acondicionadas em sacos plásticos individuais e identificados por tratamento, baia e número do animal, sendo armazenadas sob congelamento.

Foram determinados os teores de matéria seca (MS), proteína bruta $(\mathrm{PB})$, matéria orgânica $(\mathrm{MO})$, energia bruta (EB), fibra em detergente neutro (FDN) e fibra em detergente ácido (FDA), segundo o esquema convencional de Weende e o Método de Partição de Fibras (Método de Van Soest), conforme SILVA (1990). Foi feita a determinação do amido (AM), utilizando-se o método enzimático descrito por POORE (1989), adaptado por PEREIRA e ROSSI JR. (1995), para leitura da glicose com Kit ENZCOLOR. A determinação do cálcio e fósforo foi feita por Espectrometria de Absorção Atômica.

Os coeficientes de digestibilidade aparente foram obtidos por intermédio do método dos indicadores, sendo a cinza insolúvel em ácido (CIA) utilizada como indicador interno. Sua determinação foi feita segundo a metodologia descrita por VAN KEULEN e YOUNG (1977) e FONTES et al. (1996).
O coeficiente de digestibilidade aparente da MS e dos demais nutrientes foi calculado pela fórmula abaixo, de acordo com SILVA e LEÃO (1979) e FONTES et al. (1996): Coef. Dig. da MS (CDMS $)=100-100 \times \frac{\% \text { indicador no alimento }}{\% \text { indicador nas fezes }}$

Coef. Dig. Nutr. $=100-100$ (\%indicador na MS do alimento $\mathrm{x} \%$ nutrientes nas fezes $)$

(\%indicador na MS das fezes x $\%$ nutrientes no alimento)

$\mathrm{Na}$ análise estatística, foi utilizado o delineamento inteiramente casualizado em esquema fatorial $2 \times 2 \times 2$, com quatro repetições para as dietas MLE + sal comum, $\mathrm{MFA}+$ sal mineral, CLE + sal comum e CFA + sal comum e três repetições para as dietas MLE + sal mineral, MFA + sal comum, CLE + sal mineral, CFA + sal mineral. Os dados de digestibilidade aparente foram analisados levando-se em consideração os efeitos principais: duas fontes de energia (milho ou casca de mandioca), duas fontes de proteína (levedura ou farelo de algodão + farinha de carne e ossos) e duas fontes de sal (comum ou mineral), bem como suas interações. Os dados experimentais foram analisados por intermédio do programa SAEG e as variáveis foram analisadas de acordo com o seguinte modelo matemático:

$\mathrm{Y}_{i j k l}=\mu+\mathrm{E}_{i}+\mathrm{P}_{j}+\mathrm{S}_{k}+\mathrm{EP}_{i j}+\mathrm{ES}_{i k}+\mathrm{PS}_{j k}+\mathrm{e}_{i j k l}$

$\mathrm{Y}_{i j k}=$ observação da digestibilidade aparente do animal $l$ que recebeu a ração com a fonte de energia do tipo $i$, fonte de proteína do tipo $j$ e fonte de sal do tipo $k$;

$\mu=$ constante comum a todas as observações;

$\mathrm{E}_{i} \quad=$ efeito da fonte de energia $i, i=1,2$;

Tabela 2 - Composição química das dietas experimentais (\%MS) ${ }^{1}$

Table 2 - Chemical composition of experimental diets (\% DM)

\begin{tabular}{lcccccccccc}
\hline Dieta & MS & PB & MO & EM $^{2}$ & FDA & FDN & AM & Ca & P & CIA \\
Diet & $D M$ & $C P$ & $O M$ & $M E$ & ADF & NDF & Starc & & AIA \\
\hline MLE $^{\mathrm{a}}$ & 47,27 & 12,69 & 96,79 & 1,97 & 19,66 & 36,17 & 35,79 & 0,39 & 0,41 & 1,77 \\
MFA $^{\mathrm{b}}$ & 47,85 & 13,36 & 94,72 & 1,70 & 26,67 & 45,70 & 26,70 & 0,72 & 0,64 & 1,66 \\
CLE $^{\mathrm{c}}$ & 47,05 & 10,88 & 95,76 & 2,37 & 24,75 & 41,22 & 30,30 & 0,52 & 0,33 & 2,34 \\
CFA $^{\mathrm{d}}$ & 47,63 & 12,38 & 94,12 & 2,17 & 30,90 & 50,11 & 22,17 & 0,81 & 0,59 & 2,05 \\
\hline
\end{tabular}

1 Dados do Laboratório de Análise de Alimentos e Alimentação e Nutrição Animal - DZO/UEM.

$2 \mathrm{Mcal} / \mathrm{kg}$ de MS.

a Dieta contendo milho e levedura.

b Dieta contendo milho, farelo de algodão + farinha de carne e ossos.

c Dieta contendo casca de mandioca e levedura.

d Dieta contendo casca de mandioca, farelo de algodão + farinha de carne e ossos.

${ }^{1}$ Data obtained from the Laboratory of Feed Analysis and Animal Nutrition DZO/UEM.

a Diet containing corn and yeast.

b Diet containing corn, cottonseed meal + meat and bone meal.

${ }^{c}$ Diet containing cassava hull and yeast.

${ }^{a}$ Diet containing cassava hull, cottonseed meal + meat and bone meal. 
$\mathrm{P}_{j} \quad=$ efeito da fonte de proteína $j, j=1,2$;

$\mathrm{S}_{k}=$ efeito da fonte de sal $k, k=1,2$;

$\mathrm{E}_{i} \mathrm{P}_{j}=$ efeito da interação da fonte de energia $\mathrm{E}_{i}$ com a fonte de proteína $\mathrm{P}_{j}$;

$\mathrm{ES}_{i k}=$ efeito da interação da fonte de energia $\mathrm{E}_{i}$ com a fonte de sal $\mathrm{S}_{k}$;

$\mathrm{PS}_{j k}=$ efeito da interação da fonte de proteína $\mathrm{P}_{j}$ com a fonte de sal $\mathrm{S}_{k}$; e

$\mathrm{e}_{i j k l}=$ erro aleatório associado a cada observação do desempenho $\mathrm{Y}_{i j k l}$.

\section{Resultados e Discussão}

O coeficiente de digestibilidade aparente da matéria seca (CDMS), proteína bruta (CDPB), matéria orgânica (CDMO), energia bruta (CDEB), fibra em detergente ácido (CDFDA), fibra em detergente neutro (CDFDN) e do amido (CDAM) encontram-se na Tabela 3.

O CDMS médio da MS das dietas foi de $56,4 \%$, inferior ao encontrado por D' OLIVEIRA et al. (1997), de $66,5 \%$, para rações com farelos de soja e canola, em condições semelhantes às deste experimento. Da mesma forma, PRADO et al. (1996), trabalhando com farelo de canola moído e peletizado, obtiveram CDMS de $64,5 \%$. Todavia, vale salientar que esses autores utilizaram a lignina como indicador interno.

Os baixos valores obtidos para o CDMS provavelmente ocorreram em função da baixa qualidade da silagem de milho (Tabela 1). Segundo PHILLIP et al. (1980), a qualidade da silagem pode provocar alteração do $\mathrm{pH}$ ruminal, que poderia comprometer os produtos finais da fermentação e a taxa de crescimento de bactérias e protozoários, prejudicando a digestibilidade dos nutrientes.

Houve interação $(\mathrm{P}<0,05)$ para o CDMS entre as fontes de energia e fontes de proteína. Com relação às fontes energéticas, o CDMS foi superior $(\mathrm{P}<0,05)$ para as dietas contendo casca de mandioca, com valor médio de $63,6 \%$, em relação às dietas contendo milho, com valor médio de 49,2\%, para ambas as fontes de proteína. SMITH et al. (1991), em um estudo para avaliar a degradabilidade ruminal in situ de alguns

Tabela 3 - Efeito da interação entre as fontes de energia e proteína sobre o coeficiente de digestibilidade aparente (\%) da matéria seca (CDMS), proteína bruta (CDPB), matéria orgânica (CDMO), energia bruta (CDEB), fibra em detergente ácido (CDFDA), fibra em detergente neutro (CDFDN) e do amido (CDAM)

Table 3 - Interaction effect between energy and protein sources on apparent digestibility coefficient (\%) of dry matter $(D M D C)$, crude protein $(C P D C)$, organic matter $(O M D C)$, gross energy (GEDC), acid detergent fiber (ADFDC), neutral detergent fiber (NDFDC) and starch (SDC)

\begin{tabular}{|c|c|c|c|c|c|}
\hline \multicolumn{6}{|c|}{$\begin{array}{l}\text { Efeitos principais } \\
\text { Principal effects }\end{array}$} \\
\hline $\begin{array}{l}\text { Fonte de energia } \\
\text { Energy source }\end{array}$ & \multicolumn{2}{|c|}{$\begin{array}{l}\text { Milho } \\
\text { Corn }\end{array}$} & \multicolumn{2}{|c|}{$\begin{array}{c}\text { Casca de mandioca } \\
\text { Cassava hull }\end{array}$} & \\
\hline $\begin{array}{l}\text { Fonte de proteína } \\
\text { Protein source }\end{array}$ & $\begin{array}{c}\text { Levedura } \\
\text { Yeast }\end{array}$ & $\begin{array}{c}\mathrm{FA}+\mathrm{FCO}^{2} \\
\text { Cottonseed meal }\end{array}$ & $\begin{array}{c}\text { Levedura } \\
\text { Yeast }\end{array}$ & $\begin{array}{c}\mathrm{FA}+\mathrm{FCO}^{1} \\
\text { Cottonseed meal }\end{array}$ & \\
\hline $\begin{array}{l}\text { Parâmetro } \\
\text { Parameter }\end{array}$ & & & & & $\mathrm{CV}^{1}$ \\
\hline CDMS & $52,8^{\mathrm{aB}}$ & $45,6^{\mathrm{bB}}$ & $66,2^{\mathrm{aA}}$ & $60,9^{\mathrm{bA}}$ & 5,6 \\
\hline $\begin{array}{l}\text { CDPB } \\
P B D C\end{array}$ & $52,0^{\mathrm{aB}}$ & $47,0^{\mathrm{bB}}$ & $65,1^{\mathrm{aA}}$ & $63,3^{\mathrm{aA}}$ & 5,1 \\
\hline $\begin{array}{l}\text { CDMO } \\
O M D C\end{array}$ & $55,4^{\mathrm{aB}}$ & $48,89^{\mathrm{bB}}$ & $69,4^{\mathrm{aA}}$ & $63,8^{\mathrm{bA}}$ & 5,2 \\
\hline $\begin{array}{l}\mathrm{CDEB} \\
C E D C\end{array}$ & $53,5^{\mathrm{aB}}$ & $47,6^{\mathrm{bB}}$ & $66,2^{\mathrm{aA}}$ & $61,6^{\mathrm{bA}}$ & 5,0 \\
\hline $\begin{array}{l}\text { CDFDA } \\
A D F D C\end{array}$ & $49,2^{\mathrm{aA}}$ & $40,8^{\mathrm{bB}}$ & $49,1^{\mathrm{aA}}$ & $51,3^{\mathrm{aA}}$ & 8,7 \\
\hline $\begin{array}{l}\text { CDFDN } \\
N D F D C\end{array}$ & $45,9^{\mathrm{aB}}$ & $38,8^{\mathrm{bB}}$ & $50,6^{\mathrm{aA}}$ & $50,6^{\mathrm{aA}}$ & 9,1 \\
\hline $\begin{array}{l}\text { CDAM } \\
S D C\end{array}$ & $67,9^{\mathrm{aB}}$ & $68,1^{\mathrm{aB}}$ & $95,1^{\mathrm{aA}}$ & $96,6^{\mathrm{aA}}$ & 2,6 \\
\hline
\end{tabular}

Médias, na linha, seguidas de diferentes letras minúsculas dentro das fontes de energia (milho ou casca de mandioca) e maiúsculas dentro das fontes de proteína (levedura ou farelo de algodão + farinha de carne e ossos) diferem $(P<0,05)$ pelo teste Tukey.

Means, within a row, followed by different small letters within the energy sources (corn or cassava hull) and capital letters within the protein sources (yeast or cottonseed meal + meat and bone meal) differ $(P<.05)$ by Tukey test.

2 Farelo de algodão + farinha de carne e ossos. (Cottonseed meal + meat and bone meal). 
alimentos, encontraram 82 e $77 \%$, respectivamente, para degradabilidade potencial da MS da casca de mandioca moída (1 mm) e do milho moído $(1 \mathrm{~mm})$. AROEIRA et al. (1996) encontraram elevado valor para a degradabilidade potencial da MS da raspa de mandioca (96\%). Portanto, a maior taxa de degradação da casca de mandioca em relação ao milho poderia explicar estes resultados. Com relação às fontes de proteína da dieta, o CDMS foi superior $(\mathrm{P}<0,05)$ para as dietas contendo levedura, com valores médios de 59,5\% em comparação às dietas contendo farelo de algodão + farinha de carne e ossos, com valores médios de 53,3\%, para ambas as fontes de energia (milho ou casca de mandioca). Isto poderia ter ocorrido em função da maior solubilização da levedura no rúmen em relação ao farelo de algodão e à farinha de carne e ossos. BERCHIELI et al. (1989) avaliaram a digestibilidade aparente de rações contendo farelo de soja ou levedura como fonte de proteína e bagaço de cana-de-açúcar hidrolisado como volumoso. A digestibilidade da MS e PB obtida por esses autores foi superior para a dieta contendo levedura (56,2 e $48,1 \%$, respectivamente) em relação à dieta contendo farelo de soja (49,4 e 42,1\%, respectivamente).

Em relação ao CDPB, o valor médio obtido foi $56,9 \%$ inferior ao encontrado por MEDRONI (1998), $63,6 \%$, que trabalhou com dietas à base de milho e triticale, como fonte de energia, e farelo de soja e levedura, como fonte de proteína.

Houve interação $(\mathrm{P}<0,05)$, para o $\mathrm{CDPB}$, entre as fontes energéticas e as fontes protéicas. Quanto às fontes protéicas, o CDPB foi superior $(\mathrm{P}<0,05)$ para as dietas contendo levedura $(52,0 \%)$ em relação às dietas contendo farelo de algodão + farinha de carne e ossos $(47,0 \%)$, tendo o milho como fonte energética. Estes resultados também poderiam ser explicados pela alta taxa de degradação da levedura. MACHADO e LIMA (1984), utilizando a levedura Saccharomyces $s p$, demostraram a ocorrência de aumento na digestibilidade da MS, MO, PB e EB dos alimentos, que, segundo os autores, foi atribuído à maior solubilidade do nitrogênio da levedura, comparado à do farelo de soja, promovendo maior disponibilidade de nitrogênio no rúmen. Por outro lado, não houve diferença no CDPB entre as fontes de proteína (farelo de algodão + farinha de carne e ossos ou levedura), quando a fonte de energia foi a casca de mandioca. Com relação às fontes energéticas, o CDPB foi superior $(\mathrm{P}<0,05)$ para as dietas contendo casca de mandioca, em relação às dietas contendo milho, provavelmente devido ao maior potencial de degradação da mandioca em relação ao milho. ZINN e DePETERS
(1991), em um experimento para avaliar a substituição do milho floculado pela mandioca, observaram que, embora ambos apresentem conteúdo de nitrogênio $(\mathrm{N})$ diferente, a taxa de passagem do $\mathrm{N}$ para o intestino delgado foi semelhante para as duas dietas, refletindo em maior síntese de $\mathrm{N}$ microbiano das dietas contendo mandioca. Segundo esses autores, o amido da mandioca é muito eficiente na síntese de proteína microbiana, contribuindo com o aumento na degradabilidade da PB.

Para o CDMO, houve interação $(\mathrm{P}<0,05)$ entre as fontes de energia e proteína. O CDMO foi maior $(\mathrm{P}<0,05)$ para as dietas contendo casca de mandioca, com valor médio de $66,6 \%$ em relação às dietas contendo milho, com valor médio de $52,2 \%$. Com relação às fontes de proteína, o CDMO foi superior $(\mathrm{P}<0,05)$ para as dietas contendo levedura, com valor médio de $62,0 \%$ em relação às dietas contendo farelo de algodão + farinha de carne e ossos, com valor médio de 56,3\%. Portanto, o maior CDMO foi obtido para a dieta composta por casca de mandioca e levedura, sendo ambas as fontes de energia e proteína de alta degradação ruminal. SMET et al. (1995), em um experimento utilizando milho e sorgo (degradação lenta) e mandioca, cevada e trigo (degradação rápida), concluíram que alimentos ricos em fibra podem apresentar maior taxa de degradação que alimentos com alto teor de amido.

Houve interação $(\mathrm{P}<0,05)$ para o CDEB entre as fontes de energia (milho ou casca de mandioca) e proteína (levedura ou farelo de algodão + farinha de carne e ossos). Com relação às fontes de proteína, o CDEB foi maior $(\mathrm{P}<0,05)$ para as dietas contendo levedura, com valor médio de $59,9 \%$, em relação às dietas contendo farelo de algodão + farinha de carne e ossos, com valor médio de $54,6 \%$, para ambas as fontes de energia. Com relação às fontes de energia, o CDEB foi maior $(\mathrm{P}<0,05)$ para as dietas contendo casca de mandioca $(63,9 \%)$ em relação às dietas contendo milho (50,6\%). O CDEB médio foi $57,2 \%$, sendo inferior ao valor médio encontrado por MEDRONI (1998), de 63,6\%, que trabalhou com duas fontes de energia (milho ou triticale) e proteína (farelo de soja ou levedura). Dessa forma, o maior CDEB foi obtido para as dietas contendo casca de mandioca e levedura. Segundo TAMMINGA (1996), a digestibilidade pode ser aumentada com melhor controle dos fatores que a determinam. Portanto, sincronização entre proteínas e carboidratos também diminui as perdas de nitrogênio no rúmen.

Para o CDFDA e CDFDN, houve interação $(\mathrm{P}<0,05)$ entre as fontes de energia e proteína. Com relação às fontes protéicas, os CDFDA e CDFDN foram superiores $(\mathrm{P}<0,05)$ para as dietas que continham levedura em relação às dietas com farelo de 
algodão + farinha de carne e ossos, tendo o milho como fonte energética. Neste caso, a levedura serviria como fonte de substrato prontamente disponível aos microrganismos do rúmen, contribuindo, portanto, para a degradação da fibra. Por outro lado, a farinha de carne e ossos não causaria o mesmo efeito por apresentar baixa degradabilidade ruminal. Para a casca de mandioca, não houve diferença no CDFDA e CDFDN entre as fontes de proteína (levedura ou farelo de algodão + farinha de carne e ossos). O CDFDA $(47,6 \%)$ e CDFDN (46,5\%) médios foram superiores aos obtidos por PRADO et al. (1995), que foi de 31,5 e $45,5 \%$, utilizando a lignina como indicador interno. MEDRONI (1998) encontrou valores superiores para o CDFDA $(65,6 \%)$ e CDFDN $(68,8 \%)$.

VILELA et al. (1990), em um estudo para avaliar o efeito da suplementação energética da silagem de capim-elefante com a raspa de mandioca, sem a adição de uréia, sobre o desempenho de novilhos e carneiros, obtiveram valores para a digestibilidade aparente de FDA e FDN, respectivamente, de 22,8 e 18,1\%, sendobastante inferiores aos valores médios de digestibilidade de FDA $(50,2 \%)$ e FDN $(50,5 \%)$ encontrados neste trabalho para as dietas contendo casca de mandioca.

Com relação às fontes de energia, o CDFDN foi superior $(\mathrm{P}<0,05)$ para as dietas contendo casca de mandioca em relação às dietas contendo milho, independente da fonte de proteína, provavelmente devido ao menor teor de amido da casca de mandioca em relação ao milho, o qual, segundo alguns autores, poderia prejudicar a digestão da fibra. HOLZER et al. (1997), avaliando o efeito da adição de mandioca como fonte de energia em dietas contendo feno e farelo de soja, observaram redução na digestibilidade da FDN, devido ao aumento do conteúdo de amido da dieta, ao se adicionar mandioca.

Da mesma forma, o CDFDA foi superior para as dietas contendo casca de mandioca em relação ao milho. Entretanto, este efeito foi observado somente quando se utilizou farelo de algodão + farinha de carne e ossos como fonte de proteína. Embora o amido da mandioca seja mais digestível em relação ao amido do milho, o menor teor de amido da casca de mandioca em relação ao milho explicaria esses resultados. O aumento no teor de amido poderia estar promovendo competição entre bactérias celulolíticas e amilolíticas pelos nutrientes, havendo redução do $\mathrm{pH}$, em função da produção de ácidos pela fermentação do amido, prejudicando a digestão da fibra. STUMPF JR. e LÓPEZ (1994), em um estudo para avaliar os efeitos de níveis de inclusão da raiz de mandioca descascada e desidratada como fonte de amido sobre o consumo e digestibilidade, observaram que o aumento na porcentagem de inclusão reduziu a digestibilidade da fibra.
MERTENS e LOFTEN (1980) sugerem que o principal mecanismo para a redução na digestibilidade da fibra, associado à adição de amido na dieta, é a redução da atividade celulolítica, devido às condições ácidas causadas pela fermentação do amido.

Para o CDAM, houve diferença $(\mathrm{P}<0,05)$ somente entre as fontes de energia (milho ou casca de mandioca). O CDAM foi superior $(\mathrm{P}<0,05)$ para as dietas contendo casca de mandioca em relação ao milho, independente das fontes de proteína (farelo de algodão + farinha de carne e ossos ou levedura). Os baixos valores encontrados para a digestibilidade do amido das dietas contendo milho pode ter ocorrido em função da baixa qualidade da silagem de milho, havendo efeito associativo negativo entre estes alimentos sobre a digestibilidade aparente do amido. RUSSEL et al. (1981), avaliando o efeito de níveis de inclusão do milho em dietas contendo silagem de milho e farelo de soja sobre a digestibilidade do amido em novilhos, encontraram para a digestibilidade do amido valor de $81,4 \%$. Os autores observaram que, com o aumento da inclusão de milho e, consequentemente, da ingestão de amido, ocorreu maior escape da fermentação ruminal do amido, reduzindo sua digestibilidade total. Nesse trabalho, observou-se maior ingestão de amido para as dietas contendo milho em relação às dietas contendo casca de mandioca (Experimento 3).

STUMPF JR. e LÓPEZ (1994) obtiveram valor de $97,8 \%$ para a digestibilidade do amido na dieta contendo feno, farelo de soja e $30 \%$ de raiz de mandioca, estando próximo ao valor obtido para a digestibilidade do amido da casca de mandioca e levedura $(95,1 \%)$, que continha $31,9 \%$ de casca de mandioca.

As fontes de sal (comum ou mineral) não influenciaram os coeficientes de digestibilidade dos nutrientes. Entretanto, houve interação $(\mathrm{P}<0,05)$ entre o milho e as fontes de sal (comum ou mineral) sobre o CDMS, CDPB, CDMO, CDFDN e CDAM (Tabela 4).

Os CDMS, CDMO, CDPB, CDFDN e CDAM foram superiores $(\mathrm{P}<0,05)$ para as dietas que continham milho e sal mineral em relação às dietas contendo milho e sal comum. A lenta taxa de degradação do milho, associada à presença de minerais no rúmen, pode ter acarretado maior eficiência microbiana na degradação dos nutrientes, aumentando a digestibilidade dessas dietas. CHRISTIANSEN e WEBB JR. (1988), trabalhando com fêmeas da raça Angus, avaliaram o efeito da adição de fontes de minerais (calcário, óxido de magnésio e outros) sobre a digestibilidade do amido e da proteína e sobre a absorção de aminoácidos no intestino delgado. Esses autores observaram que a adição das fontes de 
Tabela 4 - Efeito da interação entre o milho e as fontes de sal (Sal ou Sal mineral) sobre o coeficiente de digestibilidade aparente (\%) da matéria seca (CDMS), proteína bruta (CDPB), matéria orgânica (CDMO), fibra em detergente neutro (CDFDN) e do amido (CDAM)

Table 4 - Interaction effect between corn and the salt sources (salt or mineralized salt) on apparent digestibility coefficient (\%) of dry matter (DMDC), crude protein $(C P D C)$, organic matter (OMDC), neutral detergent fiber (NDFDC) and starch (SDC)

Fonte de energia

Energy source

Fonte de Sal

Salt source

Parâmetro

Milho

Parameter

\begin{tabular}{llll}
\hline CDMS & $45,7 \mathrm{~b}$ & $50,9 \mathrm{a}$ & 7,7 \\
$D M D C$ & & & \\
CDPB & $45,9 \mathrm{~b}$ & $51,5 \mathrm{a}$ & 4,9 \\
$P B D C$ & & & \\
CDMO & $48,8 \mathrm{~b}$ & $53,7 \mathrm{a}$ & 7,0 \\
OMDC & & & \\
CDFDN & $37,6 \mathrm{~b}$ & $44,9 \mathrm{a}$ & 9,0 \\
NDFDC & & & \\
CDAM & $66,4 \mathrm{~b}$ & $69,1 \mathrm{a}$ & 2,4
\end{tabular}

SDC

Médias, na linha, seguidas de letras diferentes são diferentes $(\mathrm{P}<0,05)$ pelo teste Tukey.

Means, within a row, followed by different letters are different $(P<.05)$ by Tukey test.

minerais não alterou a digestibilidade do amido, mas aumentou o fluxo de proteína para o duodeno e a absorção dos aminoácidos no intestino delgado.

\section{Conclusões}

Os coeficientes de digestibilidade da MS, MO e EB foram maiores para as dietas contendo levedura em relação àquelas com farelo de algodão + farinha de carne e ossos. O mesmo ocorreu com o coeficiente de digestibilidade da PB, FDA e FDN, porém somente para as dietas contendo milho como fonte de energia. Não houve influência das fontes protéicas sobre a digestibilidade do amido.

A cascade mandioca promoveu maior digestibilidade dos nutrientes em relação ao milho, independente da fonte protéica. Entretanto, para o CDFDA, não houve diferença entre as fontes energéticas, quando se utilizou a levedura como fonte protéica.

\section{Referências Bibliográficas}

AGRICULTURAL AND FOOD RESEARCH COUNCIL AFRC. 1995. Technical committee on responses to nutrients: energy and protein requirements of ruminants. Wallinford: CAB INTERNATIONAL. 159p.
AROEIRA, L.J.M., LOPES, F.C.F., DAYRELL, M.S. 1996. Degradabilidade de alguns alimentos no rúmen de vacas Holandês/Zebu. R. Soc. Bras. Zootec., 25(6):1176-1185.

BERCHIELLI, T.T., ANDRADE, P., CARVALHO, J.L. et al. 1989. Digestibilidade de rações contendo bagaço de cana hidrolisado, suplementadas com farelo de soja, levedura e rolão de milho. R. Soc. Bras. Zootec., 18(6):532-537.

CHRISTIANSEN, M.L., WEBB JR., K.E. 1988. Starch and protein digestibility and amino acid absorption in beef cattle fed a high concentrate diet with mineral acid-neutralizing compounds. Anim. Sci. Res., 7:100-105.

D'OLIVEIRA, P.S., PRADO, I.N., SANTOS, G.T. et al.1997. Efeito da substituição do farelo de soja pelo farelo de canola sobre o desempenho de novilhas Nelore confinadas. R. Bras. Zootec., 26(3):568-574.

DUTRA, A.R., QUEIROZ, A.C., PEREIRA, J.C. et al.1997. Efeito dos níveis de fibra e das fontes de proteína sobre o consumo e digestão dos nutrientes em novilhos. R.. Bras. Zootec., 26(4):787-796.

FONTES, C.A.A., OLIVEIRA, M.A.T., LANNA, R.P.1996. Avaliação de indicadores na determinação da digestibilidade em novilhos. R. Soc. Bras. Zootec., 25(3):529-539.

HOLZER, Z., AHARONI, Y., LUBIMOV, V. et al. 1997. The feasibility of replacement of grain by tapioca in diets for growing-fattening cattle. Anim. Feed Sci. Techn., 64:133-141.

KOMISARCZUK-BONY, S., DURAND, M. 1991. Effects of minerals on microbial metabolism. Rumen microbial metabolism and ruminant digestion. INRA, Editions, Paris. p.179-198.

MACHADO, P.F., LIMA, U.A. 1984. Valor nutritivo da levedura (Saccharomyces ssp.) para vacas em lactação. R. Soc. Bras. Zootec., 13(4):509-519.

MEDRONI, S. Efeito da combinação de carboidratos e proteínas sobre a degradabilidade, digestibilidade e desempenho de novilhas Nelore confinadas. Maringá: UEM, 1998. 46p. Dissertação (Mestrado em Zootecnia) - Universidade Estadual de Maringá, 1998.

MERTENS, D.R., LOFTEN, J.R. 1980. The effect of starch on forage fiber digestion kinetics in vitro. J. Dairy Sci., 63:1437.

NATIONAL RESEARCH COUNCIL - NRC. 1996. Nutrient requeriments of beef cattle, Washington, D.C. 242 p.

PEREIRA, J.R.A., ROSSI JR., P. 1995. Manual prático de avaliação nutricional de alimentos. Piracicaba: FEALQ. 25p.

POORE, M.H., ECK, T.P., SWINGLE, R.S. et al. Total starch and relative starch avaliability of grains. In: BIENAL CONFERENCE ON RUMEN FUNCTION, Chicago, 1989. Abstracts... Chicago, v.20, p.35, 1989.

PRADO, I.N., PINTO, A.A., ZEOULA, L.M. et al.1996. Farelo de canola farelado, moído e peletizado sobre a digestibilidade aparente de novilhas Nelore confinadas. Rev. Unimar, 18(3):567-575.

PHILIP, L.E., BUCHANAN-SMITH, J.G., GROVUM, W.L.1980. Effect of ensiling whole plant corn on voluntary intake, rumen fermentation, retention time and rate of digestion in esteers. J. Anim. Sci., 51(4):1003-1010.

RUSSEL, J.R., YOUNG, A.W., JORGENSEN, N.A. 1981. Factors affecting starch digestibility with special emphasis on sorghum and corn. J. Anim. Sci., 63(5):1171-1176.

SILVA, D.J. 1990. Análise de alimentos: métodos químicos e biológicos. Viçosa, UFV. 165p.

SILVA, J.F.C., LEÃO, M.I. 1979. Fundamentos de nutrição dos 
Rev. bras. zootec.

ruminantes. Piracicaba: Livroceres. 380p.

SMET, A.M., BOEVER, J.L., BRABANDER, D.L. et al. 1995. Investigation of dry matter degradation and acidotic effect of some feedstuffs by means of in sacco and in vitro incubations. Anim. Feed Sci. Tech., 51:297-315.

SMITH, O.B., IDOWU, O.A., ASAOLU, Y.A. et al. 1991. Comparative rumen degradability of forages, browse, crop residues and agricultural by-products. Lvstck Rural, $3(2): 1-7$.

STUMPF JR., W., LÓPEZ, J. 1994. Consumo e digestibilidade em dietas suplementadas com raiz de mandioca desidratada. EMBRAPA/CPACT. Arch Latinoam. Prod. Anim., 21(1):59-68.

TAMMINGA, S. 1996. A review on enviromental impacts of nutritional strategies in ruminants. J. Anim. Sci., 74:3112-3124

VAN KEULEN, J., YOUNG, B.A. 1977. Evaluation of acidinsoluble as as a natural marker in ruminant digestibility studies. J. Anim. Sci., 44(2):283-287.
VAN SOEST, P.J. 1994. Nutritional ecology of the ruminant. 2 ed., London: Constock Publishing Associates. 476p.

VILELA, D., SILVA, J.F.C., GOMIDE, J.A. et al. 1990. Suplementação da silagem de capim-elefante (Pennisetum purpureum, Schum) com alto nível de uréia. R. Soc. Bras. Zootec., 19(4):257-277.

ZINN, R.A., DePETERS, E.J. 1991. Comparative feeding value of tabioca pellets for feedlot cattle. J. Anim. Sci., 69:47264733.
Recebido em: 21/01/99

Aceito em: 14/06/99 